\title{
Effects of Stem Cutting Types, Position and Hormonal Factors on Rooting in Stevia Rebaudiana Bertoni
}

\author{
Raji Akintunde Abdullateef (Corresponding author) \\ Kulliyyah of Science, International Islamic University Malaysia (IIUM) \\ 25200 Kuantan, Pahang, Malaysia \\ Tel: 60-1-2914-1037_E-mail: abdullateef_raji@yahoo.com \\ Mohamad Osman \\ Kulliyyah of Science, International Islamic University Malaysia (IIUM) \\ 25200 Kuantan, Pahang, Malaysia \\ Tel: 60-9-571-6759 E-mail: mbopar2004@yahoo.com
}

\begin{abstract}
Received: March 23, $2011 \quad$ Accepted: May 3, $2011 \quad$ Online Published: December 1, 2011
doi:10.5539/jas.v4n1p49

URL: http://dx.doi.org/10.5539/jas.v4n1p49
\end{abstract}

This research was financed by International Islamic University Malaysia (IIUM) under Endowment Grant EDW A10-155-0702

\begin{abstract}
Stevia rebaudiana Bertoni, a compositae, originated from Paraguay. It is propagated by stem cuttings. Leaves' glycosides are about 300 times sweeter than sugar and safe for diabetic patients. In Malaysia, techniques for stevia mass production are limited. Varieties MS012 and MS007 obtained from MARDI were studied. For each variety, cuttings made were: (i) young apical shoot (ii) old apical shoot and (iii) non apical shoot. They were treated with six concentrations of IBA ranging from 1.9 to $2.5 \mathrm{mM}$, and were placed in micro cutting chambers with the control. Characters studied were: (i) number of days for rooting, and (ii) root number at emergence. Analysis of variance revealed there were significant differences between characters at probability level $\mathrm{p}<0.05$. Cuttings from young apical shoots of MS012 and MS007 rooted on $5^{\text {th }}$ day with root number ranging from 2.8 to 13.8. IBA $2.3 \mathrm{mM}$ was optimal. Young apical cuttings of either variety treated with the IBA $2.3 \mathrm{mM}$ were ideal.
\end{abstract}

Keywords: Stevia rebaudiana, Glycosides, IBA, Stem cuttings, Apices, Diabetics, Micro cutting chambers

\section{Introduction}

The Worldwide demand for a high potency sweetener substitute to sugar increases year in year out, more so as a high percentage of the world population becomes increasingly diabetic. (Marc, 2008). The alternative natural sweetener at hand has been stevia plant. Stevia, also known as sweet leaf, or sugar leaf is a genus of about 150 species of herbs and shrubs (Robert, 2010), a member of the family Compositae and a native to Paraguay (Mark, 2009).

Stevia rebaudiana Bertoni is one of 154 members of the genus stevia and one of only two that produce sweet steviol glycosides (Soejarto et al. 1982, 1983). It is native to subtropical and tropical South America and Central America (Robert, 2010). Stevia was first brought to the attention of Europeans in 1887 when M.S. Bertoni learned of its unique properties from the Paraguayan Indians and Mestizos (Lewis, 1992). Various reports cited by Lewis (1992) indicated that it was long known to the Guarani Indians of the Paraguayan highlands who called it caá-êhê, meaning sweet herb. The leaves were used either to sweeten tea or as a general sweetening agent.

A substance called rebiana which is a trade name for zero-calorie sweetener containing mainly steviol glycoside is extracted from stevia. (Mark, 2009). Stevia is also rich in flavonoids and terpenes. Other constituents are stevioside (C38 H60 O18) which is considered sweetest in stevia, steviolbioside, rebaudiosides (C44 H70 O23) A-E, dulcoside ; chemicals like caffeic acid, campesterol, chlorogenic acid, chlorophyll, diterpene glycosides, 
dulcosides A-B, and formic acid. An extract of one or more of the glycosides may be up to 300 times sweeter than sugar (Morita et al, 2009; Duke, 1993).

Since the 1970s, stevia extracts have been widely used in many countries as a sugar substitute. In Japan, for instance, stevia extracts account for about $5.6 \%$ of the sweetener market (Strauss 1995).

Leaves of stevia are dehydrated in sunshine or heaters, fresh leaves give bitter taste. Dry leaves are further powdered to be used as a sweetener. Leaves are preferably collected in autumn. Dead leaves and black leaf spots diseases occur specifically to Stevia and are caused by Septoria fungus and Alternaria, these fungi live in soil. (Morita et al 2009).

Other process of obtaining the sweetener comprises of extracting dried leaves of stevia containing 2.56 times more of rebaudioside A than stevioside with water or aqueous solvent and isolating sweetening components from the resulting extract (Morita et al, 2000).

It is considered as a good substitute of sugar. Diabetic patients can take stevia product available in market as it lowers down the sugar level, giving the sweet taste of sugar. It is a non-caloric sweetener, the sweet compounds pass through the digestive process of the body without chemically breaking down, thus making stevia a safe substance for consumption for people who need to reduce the sugar content of their blood (Strauss, 1995).

From most of the previous work, stevia has been reported to have no adverse effect on humans (Brandle and Rosa, 1992). It has been used for centuries by the Guarani Indians of Paraguay, where the plant originated from, as sweeteners for mate tea (Goettemoeller and Ching, 1999).

China currently produces more than $80 \%$ of stevia, and $90 \%$ of it goes to Japan for production of natural sweeteners. The use of stevia extract as a table-top sweetener is well known. The trend is that more countries are giving approval to the use of rebaudioside A as a food supplement.

\subsection{Plant Description}

Stevia exists as both herbs and shrubs (Robert, 2010). The plant, under cultivation can reach up to $1 \mathrm{~m}$ or more in height (Shock, 1982). It possesses an extensive root system and brittle stems producing small, elliptic leaves. The leaves are sessile and oppositely arranged. They are lanceolate to oblancoelate in shape, and are serrated above the middle. Trichome structures on the leaf surface are of two distinct sizes, one large (4-5 $\mu \mathrm{m})$, and one small $(2.5 \mu \mathrm{m})$ (Shaffert and Chetobar 1994b). The tiny white florets are perfect, borne in small corymbs of 2-6 florets. Corymbs are arranged in loose panicles. Oddone (1997) considered stevia to be self-incompatible and insect pollinated. Additionally, he considered "clear" seeds to be infertile. Seeds are contained in slender achenes, about $3 \mathrm{~mm}$ in length. Each achene has about 20 persistent pappus bristles.

\subsection{Cultivation}

It is commercially cultivated in many parts of Brazil, Paraguay, Uruguay, Central America, Thailand and India and China. It prefers moist, sandy and loamy soil with high organic matter and adequate drainage. It tolerates a wide range of soil $\mathrm{pH}$. It also prefers partial shade with considerate summer sunshine (Rhonda, 2004)

Stevia is grown as a perennial in subtropical regions including parts of the United States, but must be grown as an annual in mid to high latitude regions, where longer days favour leaf yield and stevioside contents (Goettemoeller and Ching, 1999).

\subsection{Stem Cutting Propagation}

The seeds of stevia show a very low germination percentage. Propagation by seeds does not allow the production of homogeneous populations, resulting in great variability in important features like sweetening levels and composition.

It is best to propagate stevia plants from cuttings or tissue culture from a plant that has proven to be successful. Growing stevia from seed normally has a very low germination success; sometimes only 10\% (Sakaguchi and Kan, 1982).

Generally, stevia is propagated through cutting because seed production is problematic in this plant (Agriculture and Industry Survey, 2005).

Cutting propagation is simply the excision of plant part and nurturing the part to grow into a genetic replica of the original or parent plant. The removed plant part is called cutting. There could be stem, root, or leaf cuttings. In this study stem cutting is considered for stevia propagation. 


\subsection{Hormonal Treatment for Rooting Stimulation}

Exogenous auxins are commonly used to improve rooting efficiency and quality of stem-cuttings. Both indole-3-butiric acid (IBA) and 1-naphtalenacetic acid (NAA) stimulate adventitious rooting.

\subsection{Moisture, Temperature and Light}

The prevailing environmental conditions in the nursery i.e. light, temperature and humidity play an important role in rooting and success growth and development stages of cuttings (Hofferman, 1979).

Stevia has the potential to become a general substitute for sugar for the Malaysian population, its products for certain niche markets (e.g. for medicinal value) are even more promising, e.g. there are more than 3 million diabetic patients in the country who are likely to benefit from it. However, Malaysia still lacks suitable varieties and mass production technologies for commercialization purpose.

This study therefore is aimed at developing a standard method for good stem micro-cutting practice and early rooting stimulation under controlled humidity, temperature and light conditions in Stevia rebaudiana.

\section{Materials and Method}

Propagation of stevia is usually by stem cuttings which takes some times to root, and requires high labour inputs, hence the need to develop easy stem cutting practice and early rooting methodology for a better agricultural practice.

Two stevia varieties were utilized, they included MS012 and MS007. For each variety, three types of stem micro cuttings were made in a slant form, these were cuttings from: (i) Young apical shoot (YAS), (ii) Old apical shoot (OAS), and (iii) Non apical shoot (NAS).

Block system was employed in the treatments for the two varieties. There were 60 cuttings each for 'YAS'; 'OAS', and 'NAS'types. The 60 cuttings in each type were divided into six groups (such that there were ten cuttings in a group). Six IBA varying concentrations were prepared, they include: 1.9, 2.0, 2.1, 2.3, 2.4, and $2.5 \mathrm{mM}$.

The experimental design was such that cuttings within a group were treated with a specific IBA concentration, until all the treatments were completed. This was carried out across the three cutting types of the two varieties.

Cuttings were deepened into IBA concentration for two seconds and were allowed to stay for 10-15 minutes. After this they were transferred into a micro cutting chamber box under controlled temperature, humidity and light conditions for rooting stimulation.

\subsection{Providing Controlled Humidity, Temperature and Light Conditions}

A mist-chamber which comprises of a polystyrene box filled with two separate layers of super-heated clay and perlite (sand like) served to provide the needed high humidity condition for stem cuttings to root. The mist-chamber propagation box was designed by Awang et al. (2009). This box was filled with water up-to a designated level and covered with a designed lid which allows light into the box. The mean value for relative humidity (RH) reading was $98.2 \%$.

The humidity condition generated in the mist-chamber propagation box and the partial shade to which the box was subjected culminated into a temperature controlled environment necessary for rooting stimulation in the stem cuttings. The mean value for temperature reading was recorded as $30.6^{\circ} \mathrm{C}$.

The box was placed under a partial shade construction in other to avert direct contact with sunlight, thereby regulating the light effect on the stem cuttings. The mean value of the light intensity utilized in this experiment during the day time was read to be 1046.8 lux.

\subsection{Best Stem Micro-Cutting Practice in stevia}

The micro-cutting propagation was carried out by cutting the stems and branches of matured stevia plant towards the apex. The cuttings used for this experiment were healthy, as wilting, and unhealthy cuttings decayed in the mist-chamber propagation box. While carrying out this experiment, the following practices were observed:

a) Matured, young and healthy stem micro-cuttings were carried out using sharp scalpel, the cuttings were made into sizes which ranged from five to seven $\mathrm{cm}$ in length.

b) The leaves attached to the cutting were reduced to about 3, 4 or 5 , at the maximum. (There may be no need to reduce the sizes of the leaves by cutting them).

c) The stem was cut to include at least a node at the distal end where the stem was inserted into the perlite layer. 
d) The cut was carried out below the distal node at a length space of about $0.7-1.0 \mathrm{~cm}$.

e) An angular cut was made instead of the common horizontal cut.

f) Cut end was inserted /dipped immediately into an IBA concentration, while in a fresh state (the cut section must not be allowed to dry out).

g) Duration of insertion was for only two seconds.

h) The dipped stem cuttings were allowed to remain for 10-15 minutes before finally inserted into the micro cutting chamber propagation box.

i) Insertion of treated cutting was done in such a way that the distal node was buried in the perlite layer (Fig. 3a).

j) Little pressure was exerted on the perlite layer surrounding each cutting in order to make it stand firm in the layer.

k) Rooted stem cuttings (Figs. 3b and 3c) were transferred into poly bags and then placed under partial shade (Fig. 3d) in order to get the young plants hardened before transferring them to field. This assisted in preventing the plants from desiccation.

1) After five to six days the young plants were transplanted into larger poly-bags and then transferred to the field (Fig. 4a) so as to grow and attain maturity (Fig. 4b).

\subsection{Application of IBA Concentrations for Rooting Stimulation in stevia}

IBA concentrations were prepared in the Tissue Culture Laboratory of the Department of Biotechnology of the International Islamic University Malaysia. The six varying concentrations prepared for this study include: 1.90, $2.00,2.10,2.30,2.46$, and $2.50 \mathrm{mM}$ of IBA solutions.

Cuttings in each group were treated with specific IBA concentration in a way that a group had an IBA concentration treatment.

These were then inserted into mist-chamber propagation box and left for some days while observations continued.

\subsection{Checking the Cuttings for Root Sprouting}

Being that the insertion medium, the perlite, constitutes loose and granular particles it was easy to remove an inserted stem cutting for root sprouting observation and scoring. This was done by carefully using forceps to lift up perlite at a lower level below the depth of insertion. By lightly shaking the cutting the particles fall off and the roots were counted and the record was taken. After the roots of a stem cutting were counted, the stem was then carefully returned back into the medium and noted.

Where there was no rooting, the cutting was immediately and carefully inserted back into the medium without allowing any bruise on it.

\section{Results and Discussions}

The results obtained in this experiment were shown in Table 1.

Most of the cuttings from YAS of MS012 and MS007 rooted on the $5^{\text {th }}$ day of different IBA $(1.90-2.50 \mathrm{mM}$ concentration) treatment with average number of roots ranging from 2.8 to 13.8 except for one of the YAS of MS007 which rooted on the $8^{\text {th }}$ day with $2.30 \mathrm{mM}$ IBA treatment.

It would be observed that as for the control experimental set up (no IBA application), the YAS rooted 7 days earlier when compared to OAS and NAS, though with lesser number of roots. Stem cuttings from OAS and NAS took 12-16 days to produce roots, but root numbers are fair in comparison to YAS.

Almost all the cuttings from OAS produced roots from 7-9 days of treatment with number of roots ranging from 2.0 to 14.8 , except for OAS of MS012 which had roots on the $6^{\text {th }}$ day. The highest number of roots (14.8) occurred in OAS of MS007 treated with $2.46 \mathrm{mM}$ IBA concentration on the $7^{\text {th }}$ day, while OAS of MS007 treated with $1.9 \mathrm{mM}$ IBA concentration had the least number of root (1.0) on the $9^{\text {th }}$ day.

As for NAS, all stem cuttings produced roots between 6-8 days of varying IBA concentration treatments. NAS of MS012 recorded the highest root number (10.3) with $2.3 \mathrm{mM}$ IBA concentration, though on the $8^{\text {th }}$ day; whereas NAS of MS007 treated with $2.00 \mathrm{mM}$ IBA concentration recorded only 1 root on the $7^{\text {th }}$ day.

The above results were subjected to analysis of variance, and histogram and line curves were also plotted in order to give the data statistical support The analysis of variance revealed that at probability level $p<0.05$, there were significant differences between groups and within groups for the variables: (i) root number at emergence (p 
$<0.018$, and (ii) number of days taken before roots emerge on different cuttings with varying IBA concentrations $(\mathrm{p}<0.001)$.

Results obtained from robust tests of equality of means further confirmed the above analysis as there were significant differences in the two variables mentioned above at $\mathrm{p}<0.05$ probability level. While the former variable had significant different value at $\mathrm{p}<0.005$, the latter had $\mathrm{p}<0.024$ value. These are indications that the different stem cuttings and the varying IBA concentrations had different influence on number of roots when they emerge on cuttings and the period (days) taken for different stem cutting types to produce roots.

Fig. 1showed a histogram with a line curve of period of rooting and the number of roots upon emergence when varying stem cuttings were treated with different IBA concentrations. It is apparent from this figure that on the $5^{\text {th }}$ day 11 number of stem cuttings produced roots, these cuttings were mainly of YAS012 and YAS007, as there was no any other stem cutting types that rooted on this day (Table 1). Of these stem cuttings, nine (81.8\%) produced high number of roots which ranged from 5 to 14 , while the remaining two (8.2\%) produced 2 to 4 roots.

On the $6^{\text {th }}$ day three stem cuttings produced roots, these cuttings comprised of OAS012, NAS012 and NAS007. Two out of the three cuttings had 4 roots each while the last one had 2. There were 11 rooted stem cuttings on the $7^{\text {th }}$ day, four $(30.8 \%)$ of these cuttings sprouted high root number, at a range of 10 to 14 roots; two (15.4\%) had 4 roots while five $(38.5 \%)$ had 2 roots each. The cuttings here constituted the OAS, the NAS and the two controls for YAS.

Four (36.4\%) stem cuttings produced high number of roots ranging from 8 to 12 on the $8^{\text {th }}$ day; two $(18.2 \%)$ had 4 roots and the remaining five (45.5\%) stem cuttings had 2 roots each. The stem cuttings here comprised of the OAS, the NAS and YAS007 treated with IBA $2.3 \mathrm{mM}$ (Table 1). On the $9^{\text {th }}$ day two stem cuttings had roots. One had 12 roots and the other had only 1 root. The cuttings here were respectively the OAS012 and OAS 007.

Only two stem cuttings had roots on the $12^{\text {th }}$ day and each had average of 6 roots. These were the two controls set up for the OAS. On the $15^{\text {th }}$ and $16^{\text {th }}$ day there was one stem cutting each that produced roots and there were 4 roots in NAS012 and an average of 3.3 roots in NAS007 respectively.

From these results if earliness and high number of root sprouting are considered across the test experiments with varying IBA concentration treatments, then YAS012 and YAS007 had higher performance than other stem cutting types including the control. This is because almost all (91.7\%) produced roots on the fifth day, and high number of roots ranging from 5 to 14 was counted on $81.8 \%$ of these stem cutting types, an unparalleled results across other studied types irrespective of the IBA treatments. Generally YAS012 had better performance than YAS007 when the two are compared as this could be observed on table 1 .

The observed performance in these two stem cuttings are not unexpected simply because the cuttings were young and bore actively dividing cells which could be easily influenced by the hormonal treatment. Furthermore, it had been established that juvenile clone of any plant species would normally perform better than the old clone (Bhusar et al., 2001). It was explicit, as shown in Table 1 and Figs. $1 \& 2$ that the production of roots on the 5th day and high number of sprouted roots observed in higher percentage of these two cuttings were largely due to influence by the hormonal treatment as the control group of the same cutting types produced roots on the $7^{\text {th }}$ day and the average number of roots only ranged between 1.8 to 2.0. The juvenility stage of these two cutting types also had influence on the studied variables, since other cuttings, OAS and NAS, which were equally subjected to the same hormonal treatments performed less when compared with the YAS on the same period of rooting and high number of roots on higher percentage of cuttings. . On this note the two factors responsible for high performance in the two YAS cuttings above are: (i) the juvenility stage and (ii) the effect of the IBA hormone.

Fig. 2 is also explicit on the effects of IBA concentrations on rooting in the stem cuttings. The utilized concentrations include a control (without IBA), 1.90, 2.00, 2.10, 2.30, 2.46 and $2.50 \mathrm{mM}$.

Generally, IBA has influence on rooting in stem cuttings (Ludwig-mullaer et al., 2005), the observed responses on stem cuttings to rooting under IBA concentration influence (Fig. 2) revealed that IBA concentrations 2.10, 2.30 and $2.46 \mathrm{mM}$ had higher influence on stem cutting rooting than the other concentrations. $57.1 \%$ of the stem cutting population was influenced by the above concentrations, while concentrations $1.90,2.00$ and $2.50 \mathrm{mM}$ had influence on $28.6 \%$ of the stem cuttings. The observed frequency on the control experiment also showed that stem cuttings in this category also had roots, though it was clear on the table that the control experiments took more time to root and had fewer roots than the test experiments, thus making all test experiments to be better off.

\section{Conclusion}

In order to achieve mass vegetative production of this sweet plants so as to facilitate commercialization at relatively cheap rate, method which include utilization of micro cutting chambers and a standard shed (Fig. 3d) 
should be employed. Young Apical Stems (YAS) should be used for replication of stevia stem cuttings - either SM012 or SM007 could be selected though the former is better than the latter. Any of the IBA concentrations $2.10,2.30$ or $2.46 \mathrm{mM}$ could be used to stimulate stem cuttings to root in five days, but $2.3 \mathrm{mM}$ is recommended.

\section{References}

Agriculture and Industry Survey. (2005). Stevia cultivation. Still a Long Way to Go in India, pp: 1-7.

Awang, Y., N.A. Rahman and Ab. K. Sandrang. (2009). Adventitious rooting in microcuttings of selected indigenous landscape trees of Malaysia. Int. J. Agric. Biol., 11: 419-424. [Online] Available: www.fspublishers.org/ijab/past-issues/IJABVOL_11_NO.../12.pdf

Bhusal, R. C., Mizutani, F., Moon, D. G., and Rutto, L. L. (2001). Propagation of Citrus stem cuttings and seasonal variation in rooting capacity. Pakistan J. Biol. Sci., 4 (11): 1294-1298.

Brandle, J. E. and Rosa, N. (1992). Heritability for yield, leaf-stem ratio and stevioside content estimated from a landrace cultivar of Stevia rebaudiana. Can. J. Plant Sci., 72:1263-1266.

Duke, J. (1993). Stevia rebaudiana. In: J. Duke, CRC handbook of alternative cash crops. CRC Press, Boca Raton, FL. p. 422-424.

Goettemoeller, J. and Ching, A. (1999). Seed germination in Stevia rebaudiana. In: J. Janick (ed.), Perspectives on new crops and new uses. ASHS Press, Alexandria, VA. p. 510-511. [Online] Available: www.lni.unipi.it/stevia/stevia/v4-510.htm

Hofferman, G. J. (1979). Humidity in controlled environment. Guide Lines for plant research. [Online] Available: www.idosi.org/abr/2(5-6)/6.pdf

Lewis, W. H. (1992). Early uses of Stevia rebaudiana (Asteraceae) leaves as a sweetener in Paraguay. Econ. Bot., 46: 336-337. http://dx.doi.org/10.1007/BF02866633

Ludwig-Mullaer, J., Vertocnik, A., and D. Town, C. D. (2005). Analysis of indole-3-butyric acid induced adventitious root formation on Arabidopsis stem segments. J. Expt. Bot., 56, Issue418, Pp. 2095- 2105. PMid:15955788. http://dx.doi.org/10.1093/jxb/eri208

Marc Santora. (2008). Concern Grows Over Increase in diabetes Around World. The New York Times Washington (2010), World population increasing over Diabetics.

Mark Stibich. (2009). About Stevia sweetener-Is it better than sugar? [Online] Available: http://longevity.about.com/od/lifelongnutrition/a/stevia-extract.htm

Morita, T., Morita, K., and Koichiro, K. (2009). Variety of Stevia rebaudiana Bertoni with a high content of Rebaudioside - A plant. Publication No:US 2009/0214753 A1. United State Patent Application Publication.

Morita Toyoshige, and Yucheng, BU. (2000). Variety of Stevia rebaudiana Bertoni. United State Patent (19). Patent no- 6,080,561. US006080561A.

Oddone, B. (1997). How to grow stevia. Technical manual. Guarani Botanicals, Pawtucket, CT.

Rhonda Janke. (2004). Farming a few Acres of Herbs: Stevia. Kansas State University. [Online] Available: http://www.oznet.ksu.edu

Robert C. Artkins. (2010). New Diet revolution. Healthier-Harvest 2009. [Online] Available: http://healthier-harvest.com/news-articles/nutritional_information/stevia.htm

Sakaguchi, M. and T. Kan. (1992). Japanese researches on stevia rebaudiana (Bertoni and stevioside. Ci, Cult., 34: 235-248.

Santora, M. (2008). Concern Grows Over Increase in diabetes Around World. The New York Times Washington (2010), World population increasing over Diabetics.

Shaffert, E. E. and Chetobar, A. A. (1994). Structure, topography and onogeny of Stevia rebaudiana (English abstr.). Botanicheskii Zhurnal, 79: 38-48.

Shock, C. C. (1982). Experimental cultivation of Rebaudi's stevia in California. Univ.

Soejarto, D. D., Compadre, C. M., Medon, P. J., Kamath, S. K., and Kinghorn, A. D. (1983). Potential sweetening agents of plant origin. II. Field search for sweet-tasting Stevia species. Econ. Bot., 37: 71-79. http://dx doi.org/10.1007/BF02859308 
Soejarto, D. D., Kinghorn, A. D., and Farnsworth, N. R. (1982). Potential sweetening agents of plant origin. III. Organoleptic evaluation of stevia leaf herbarium samples for sweetness. J. Nat. Prod., 45: 590-599. PMid:7153776. http://dx.doi.org/10.1021/np50023a013

Stibich, M. (2009). About Stevia sweetener - Is it better than sugar? [Online] Available: http://longevity.about.com/od/lifelongnutrition/a/stevia-extract.htm

Strauss, S. (1995). The perfect sweetener? Technol. Rev, 98:18-20.

Whitaker, J. (1995). Sweet justice: FDA relents on stevia. Human Events, 51:11.

Table 1. Shows the responses of different stem cutting types to varying IBA concentrations in MS012 and MS007 varieties of Stevia rebaudiana

\begin{tabular}{|c|c|c|c|c|c|c|c|c|c|c|c|c|c|c|c|c|c|}
\hline \multirow{3}{*}{$S / N$} & \multirow{3}{*}{$\begin{array}{l}\text { STEM } \\
\text { CUT } \\
\text { TYPES }\end{array}$} & \multirow{3}{*}{$\begin{array}{l}\text { MS } \\
012\end{array}$} & \multirow{3}{*}{$\begin{array}{l}\text { MS } \\
007\end{array}$} & \multicolumn{12}{|c|}{ IBA CONCENTRATIONS (mM) } & \multirow{2}{*}{\multicolumn{2}{|c|}{ CONTROL }} \\
\hline & & & & \multicolumn{2}{|c|}{1.90} & \multicolumn{2}{|c|}{2.00} & \multicolumn{2}{|c|}{2.10} & \multicolumn{2}{|c|}{2.30} & \multicolumn{2}{|c|}{2.46} & \multicolumn{2}{|c|}{2.50} & & \\
\hline & & & & TD & $\begin{array}{l}\text { AV. } \\
\text { NR }\end{array}$ & TD & AV.NR & TD & AV.NR & TD & AV.NR & TD & AV.NR & TD & AV.NR & TD & $\begin{array}{l}\text { AV. } \\
\text { NR }\end{array}$ \\
\hline 1. & YAS & $\sqrt{ }$ & & 5 & 5.2 & 5 & 7.0 & 5 & 13.8 & 5 & 12.0 & 5 & 11.1 & 5 & 12.6 & 7 & 1.8 \\
\hline 2. & YAS & & V & 5 & 10.0 & 5 & 4.2 & 5 & 2.8 & 8 & 6.0 & 5 & 6.8 & 5 & 10.6 & 7 & 2.0 \\
\hline 3. & OAS & $\sqrt{ }$ & & 9 & 11.3 & 8 & 5.2 & 8 & 2.2 & 6 & 4.0 & 7 & 13.1 & 7 & 4.0 & 12 & 5.7 \\
\hline 4. & OAS & & V & 9 & 1.0 & 8 & 4.0 & 8 & 2.0 & 7 & 7.5 & 7 & 14.8 & 7 & 3.0 & 12 & 5.2 \\
\hline 5. & NAS & V & & 6 & 2.0 & 7 & 2.2 & 8 & 1.0 & 8 & 10.3 & 8 & 8.5 & 8 & 2.7 & 15 & 4.0 \\
\hline 6. & NAS & & V & 8 & 2.0 & 7 & 1.0 & 8 & 2.4 & 6 & 4.8 & 7 & 10.0 & 7 & 2.0 & 16 & 3.3 \\
\hline
\end{tabular}

KEY: YAS - young apical shoot; OAS - old apical shoot; NAS - non apical shoot; MS - MARDI stevia; IBA -indole3-butyric acid; TD - time duration (days); AV. NR. - Average number of roots.

\section{RESPONSE OF VARYING STEM CUTS TO IBA CONCENTRATIONS IN}

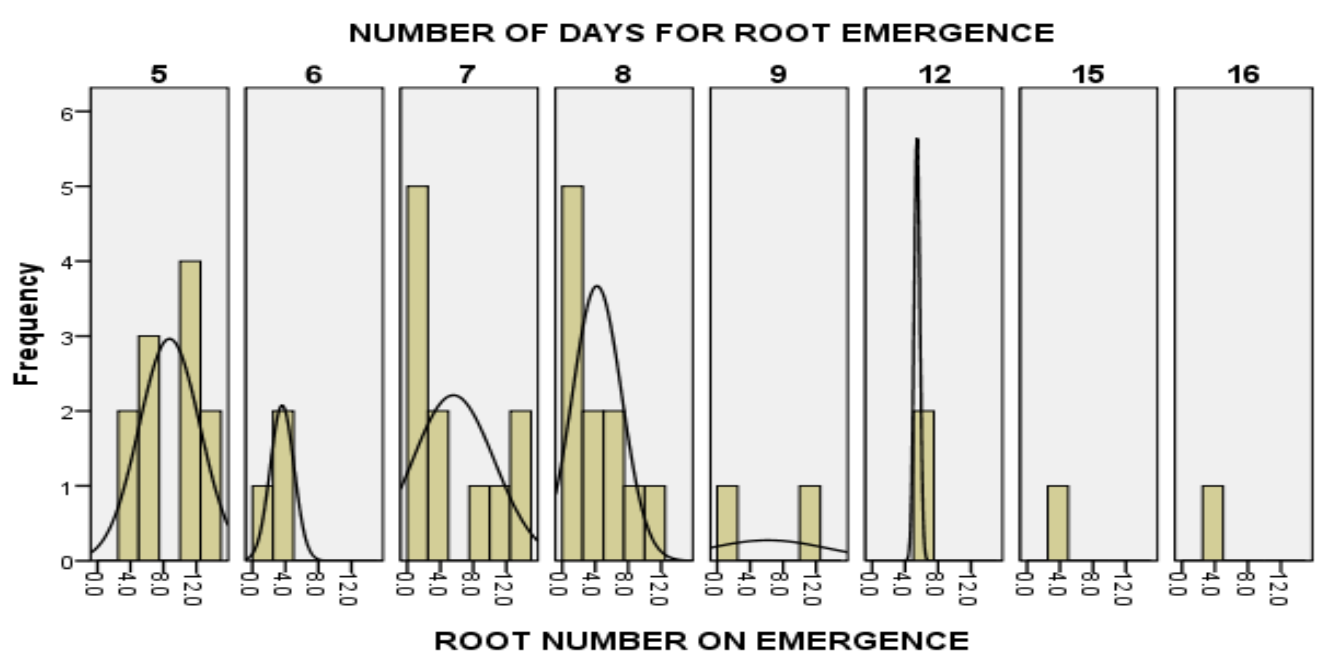

Figure 1. Period (days) of rooting in stevia stem cutting types treated with different IBA concentrations 


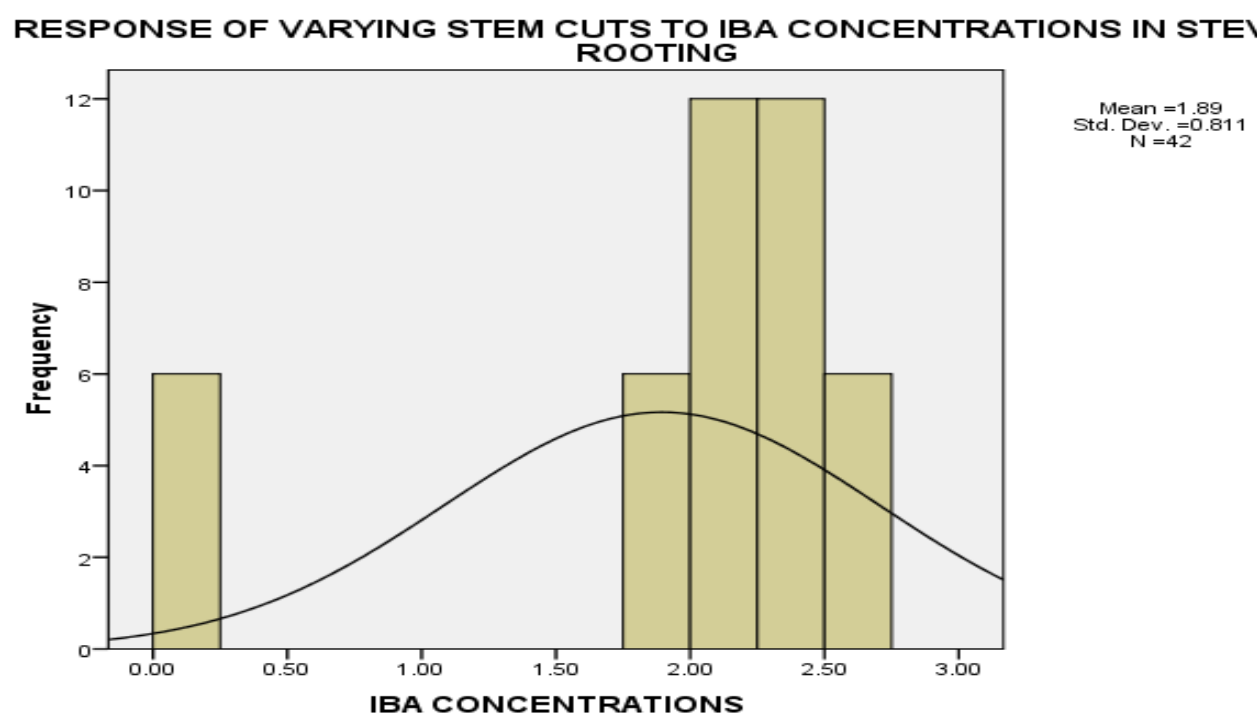

Figure 2. Responses of stem cutting types in Stevia to varying concentrations of IBA for rooting
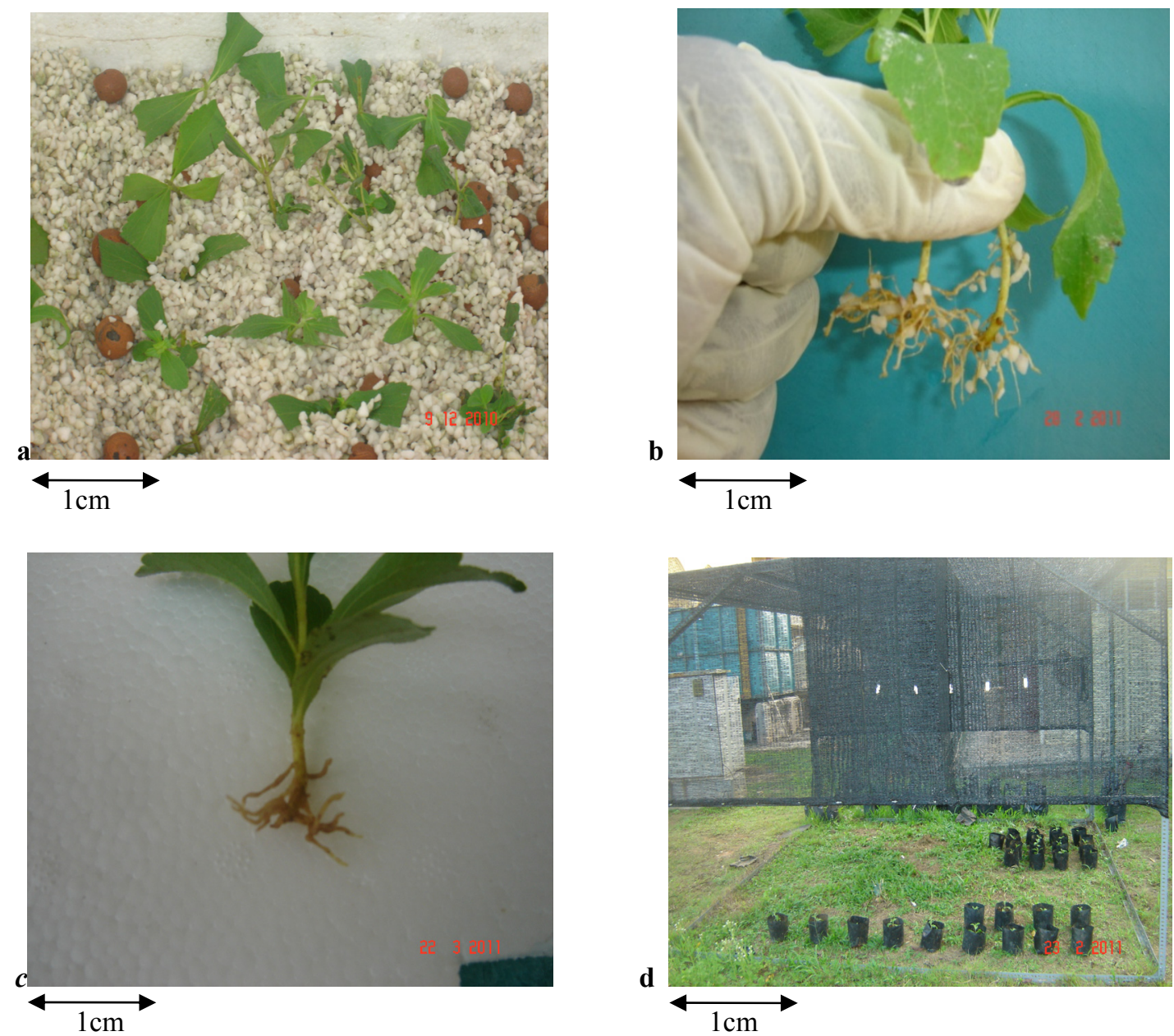

Figure 3. Showing (a) young apical stem cutting inserted in perlite of mist-chamber popagation box, (b) rooted stem cuttings frehly removed from mist-chamber popagation box, (c) a stem cutting with well developed matured roots. (d) shed where rooted cuttings were temporarily kept for few days in polybags 

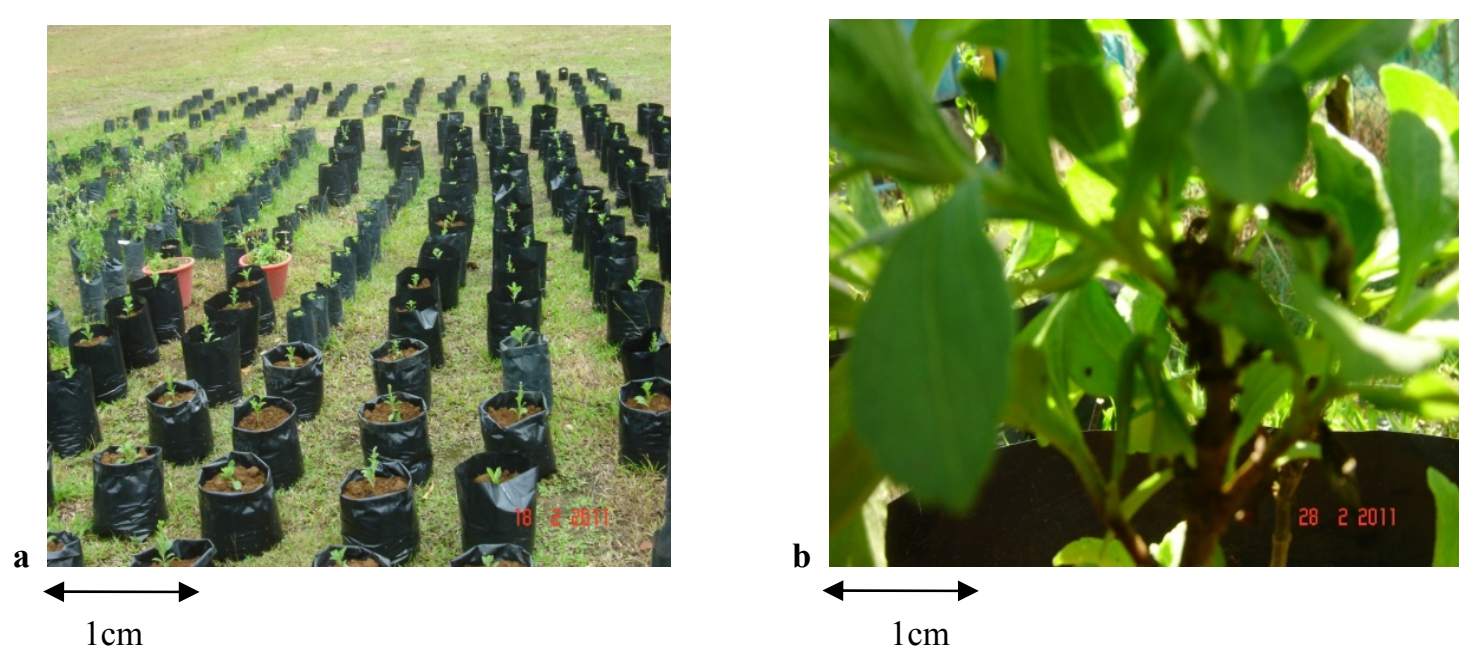

Figure 4. (a) rooted cuttings transferred to the field in a larger polybags, (b) matuerd stevia in a large polybags. 